\title{
Comparative Studies on Load Frequency Control for Islanded Distribution Network Connected with Mini Hydro
}

\author{
Javed Laghari, Hazlie Mokhlis, Member IEEE, A. B. Halim Abu Bakar Member IEEE, Hasmaini \\ Mohammad, Student Member IEEE
}

\begin{abstract}
IEEE working group on prime movers recommended different governors for hydro power plants. This paper presents the comparative studies on all of these governors for mini hydro power plants (MHPP) operating in parallel and supplying power to distribution network. The purpose of this study is to find their suitability in controlling the frequency of the system for large load variations in an islanded distribution network. The mini hydro power plant with its distribution network is modeled in PSCAD software. The mechanical hydraulic governor, electro hydraulic PID governor, electro-hydraulic PI governor and Enhanced governor are evaluated one by one to find the best response in controlling frequency when disturbance occurs. The load variations from $10 \%$ to $50 \%$ both addition and reduction are tested for every governor. This study will assists in selecting a particular governor for isolated mode, interconnected mode as well as for islanding mode of operation in distributed generation.
\end{abstract}

Index Terms - Distribution network, Frequency response, Governor Controller, Islanded network.

\section{INTRODUCTION}

$\mathrm{M}$ ini hydro power plants are working as one of the most renewable energy source because of its environment friendly operation as well as it is more predictable and concentrated energy source as compared with other available sources(like wind or solar). Mini hydro power plants are very useful technologies to be considered for rural electrification in most of the developing countries. The potential of mini hydro and its use in different countries all over the world is described in detail in [1]. According to the paper, 40GW of electrical energy demand is fulfilled by mini hydro power plants and has a global potential of more than $100 \mathrm{GW}$. UK and China produces $100 \mathrm{MW}$ and $15 \mathrm{GW}$ of electricity from mini hydro power plants [1]. Canada has more than 160 sites for micro hydro power plants that can supply power to remote regions which are not connected to grid [2]. Mini hydro contributes 93.3MW in Greece through 50 mini hydro power plants [3]. Sri Lanka has a mini hydro potential of 97.4MW [4]. Recently Malaysia has identified a micro hydro potential of $28.9 \mathrm{MW}$

This work was supported by Government of Malaysia under E-Science Fund Grant (Grant code: 06-01-03-SF0562).

Javed Laghari is with Department of Electrical Engineering, Faculty of Engineering, University of Malaya, Malaysia. (e-mail: javedahmedleghari@gmail.com). The author is thankful to Quaid-e-Awam University of Engineering Science \& Technology Nawabshah, Pakistan for their financial support to this study through HEC project.

Hazlie Mokhlis, Ab. Halim Abu Bakar are with Department of Electrical Engineering, Faculty of Engineering, University of Malaya, Malaysia. (e-mail: hazli@um.edu.my,a.halim@um.edu.my)

Hasmaini Mohamad is with Faculty of Electrical Engineering, University of Teknologi Mara, Shah Alam, Malaysia (e-mail: hasmaini@hotmail.com) from its different regions [5]. It is proved that a Pico hydro of $380 \mathrm{KW}$ when compared with its equivalent coal fired plant saves around 950 tons of $\mathrm{CO}_{2}, 12$ tons of $\mathrm{SO}_{\mathrm{X}}$ and 5 tons of $\mathrm{NO}_{\mathrm{X}}[6]$.

Mini hydro with other energy sources supplies electricity to grid in the form of distributed generation. In distributed generation the phenomena of islanding is performed for the reliability of power system to continue its supply even in the case of power failure. When system becomes islanded the frequency of the system is severely disturbed resulting in high oscillation in system frequency. The operation of mini hydro power plant during islanding test is given in [7]. The intentional islanding tests are performed to check the reliability of system as discussed in [8]-[9].

Mini hydro power plants (MHPP) are complex and nonlinear power systems due to nonlinear behavior of hydro turbine so in these power plants the frequency and voltage of the system varies continuously because of its slow response in balancing load demand. These power plants employ different control techniques for maintaining the voltage and frequency within range. Voltage is controlled by the change of excitation and frequency is balanced by making generation equal to load demand using governor control. There are different governor used for controlling the frequency within range but so far none has compared all type of governors to show their response and suitability for isolated mode, interconnected mode or for islanding operation in distributed generation.

Considering the need of suitable model for islanded distribution network, this paper compares the response of all these basic governors in terms of overshoot, undershoot and time taken for system frequency to recover its original value after coming out from load disturbance. The reference [10][12] deals with basics of hydro governor control with Proportional Integral Derivative (PID) control, simple PI control and its limitations in hydro power plants.

\section{MAthematical MODELiNG OF DIFFERENT MHPP COMPONENTS}

The mini hydro power plant mainly consists of governor, turbine and generator for conversion of mechanical energy into electrical energy. The basic function of governor is to control the speed of the generator so that its frequency remains constant. The IEEE proposes four recommended governors for controlling the frequency of system within permissible limits [13]. The guide for mini hydro power plants, control and hydro turbine is explained in [14]-[16].

The conventional mechanical hydraulic governor is older one and consists of mechanical and hydraulic components. This governor uses permanent droop characteristics for the 
stable operation. The permanent droop characteristics are used for equitable load sharing between generating units. As hydro turbines have a non-linear response due to water inertia. So a large transient droop characteristic is used for stable control performance having a long resettling time. A dashpot is used to provide transient droop compensation which can be bypassed if desired. Speed sensing, permanent droop feedback and computing functions are achieved through hydraulic components.

The gate position of turbine is controlled by using the servomotor, which adjusts water flow to produce power according to load connected. A servomotor is a precision electric motor which causes motion in rotation in proportion to a supplied electrical command signal. The transfer function for relay valve and gate servomotor is given by [17]:

$$
\frac{g}{b}=\frac{K s}{s(1+s T p)}
$$

Where $K_{S}$ is the servo gain and $T_{P}$ is the pilot valve / servomotor time constants. A dashpot transfer function is given by [17]:

$$
\frac{d}{g}=R t \frac{s T R}{(1+s T R)}
$$

Where $R_{T}$ is temporary droop and $T_{R}$ is the reset time of the temporary droop.

Fig.1 shows the block diagram representation of mechanical hydraulic governor.

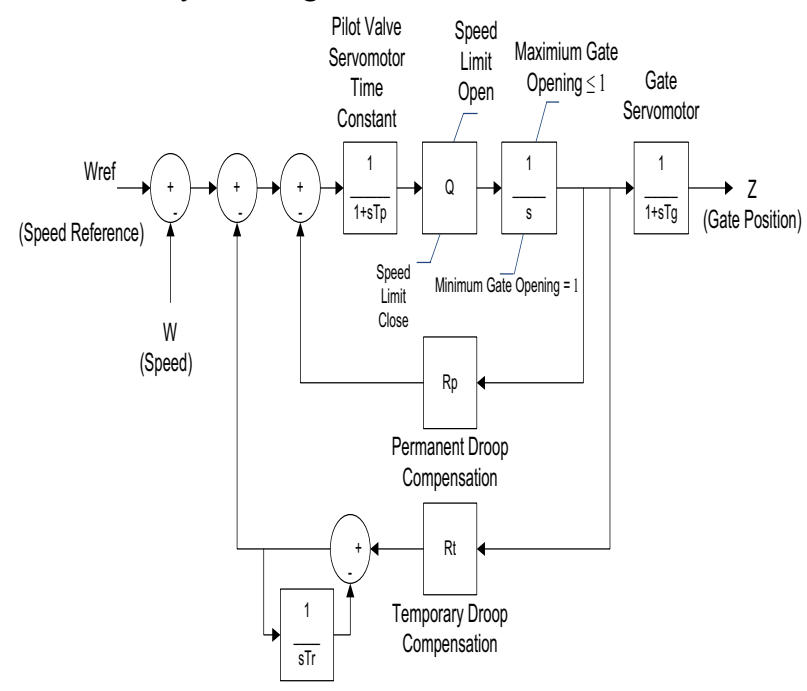

Fig.1 Mechanical Hydraulic Governor

Modern hydraulic turbine governor uses electro-hydraulic systems because electric components offer good performance and flexibility in comparison to mechanical components. Their operation remains same, only speed sensing, permanent droop, temporary droop and other measurement are performed electrically. These electro hydraulic governors are provided with PID control known as electro hydraulic PID governor which controls the system frequency under high transient and overshoot. The proportional term (P) treat the present control error and integral term (I) treats the past control error and derivative term (D) treats the future control error.
This governor has the advantage that overshoot in frequency can be minimized by changing the derivative term and steady state error is eliminated by varying the integral term of electro hydraulic PID governor. The derivative term is very useful for controlling the system operating in isolated mode but it results in excessive oscillation in case of interconnected operation. A simple PI governor can also be used by putting the derivative term equal to zero in electro hydraulic PID governor but this governor usually eliminates the steady state error and cannot minimizes the overshoot within the frequency. The block diagram representation of electro hydraulic PID governor is shown in Fig. 2.

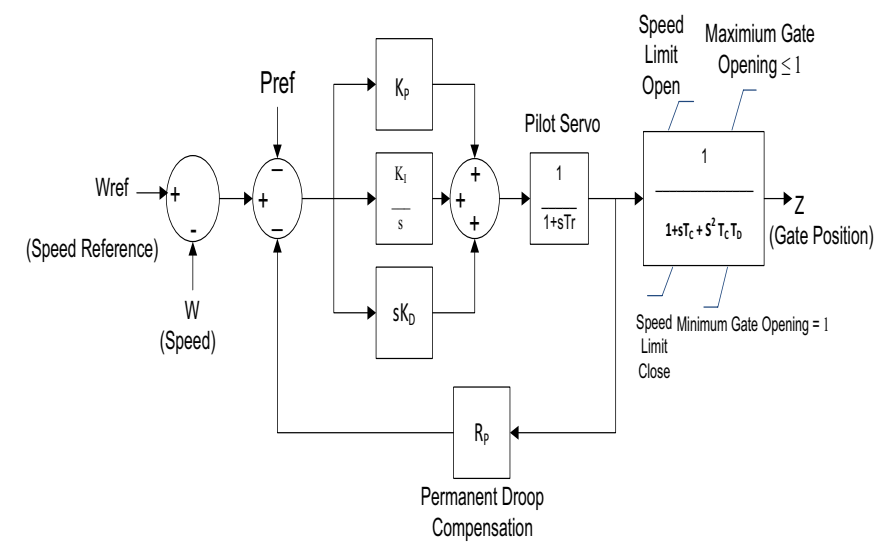

Fig. 2 Electro-Hydraulic PID Governor

The fourth governor considered for comparison is enhanced governor for load rejection studies. This governor provides jet deflector valve and relief valve for satisfactory operation but in this paper the governor is considered without jet deflector and relief valve in its operation. The block diagram representation of this governor is shown in Fig. 3.

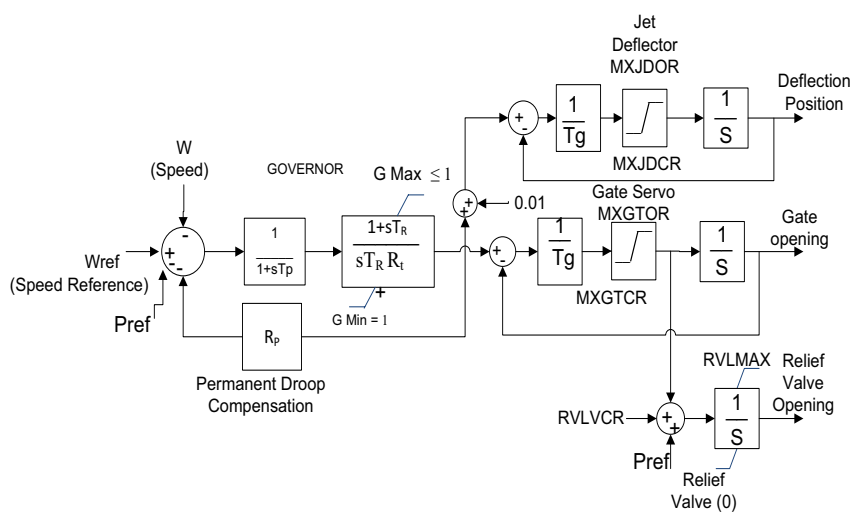

Fig.3 Enhanced Governor for load rejection studies

The hydro turbine is a mechanical device which converts the potential energy of the water head into mechanical energy. The classical transfer function of hydraulic turbine is as given in [18].

$$
\frac{\Delta P m}{\Delta G}=\frac{1-T w S}{1+0.5 T w S}
$$


Where $\Delta P m$ shows the turbine mechanical output power in per unit and $\Delta G$ shows the gate opening of turbine in per unit and $T_{w}$ is water starting time of turbine. The hydraulic turbine considered in this paper is of non-elastic water column without surge tank.

The mechanical energy obtained from hydro turbine is supplied to generator shaft for converting it into electrical energy or power. It should be noted that some mini hydro power plants operating in isolated mode uses electronic load controller for controlling turbine speed. This is done by varying the amount of power fed into a ballast load. The governor maintains a constant load on generator in spite of changing user loads. In this situation power plant has no flow regulating devices and governor control systems as described in [19]-[21].

\section{CASE STUdies}

In order to analyze the effectiveness of different load frequency control techniques in mini hydro power plant, a typical example considering two mini-hydro power plants operating in parallel is modeled in PSCAD software. The system supplied load to a distribution network having $70 \%$ of the load of its capacity. Fig. 4 shows the model of the mini hydro power plants with distribution network. The detail of Fig. 4 is depicted in Appendix B (Fig. 11). The pi-section model of transmission network is considered in this case. The details of the system along with data are given in Appendix. A. The response of the governors is checked on six cases; three cases for increase in load and three for decrease in load in order to observe significant changes.

(1) $20 \%$ load is suddenly disconnected. (from $70 \%(2.5 \mathrm{MW})$ to $50 \%(1.8 \mathrm{MW}))$

(2) $20 \%$ load is suddenly increased. (from $50 \%$ to $70 \%$ )

(3) $30 \%$ load is suddenly disconnected. (from $70 \%(2.5 \mathrm{MW})$ to $40 \%(1.44 \mathrm{MW}))$

(4) $30 \%$ load is suddenly increased. (From $40 \%$ to $70 \%$ )

(5) $50 \%$ load is suddenly disconnected. (from $70 \%(2.5 \mathrm{MW})$ to $20 \%(0.72 \mathrm{MW}))$

(6) $50 \%$ load is suddenly increased. (From $20 \%$ to $70 \%$ )

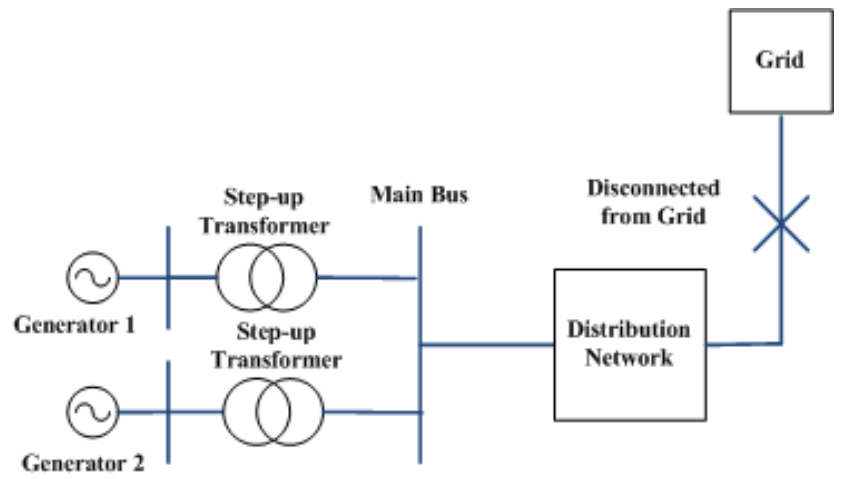

Fig. 4 The model for islanding operation case studies

\section{Simulation Results}

\section{A. Case\#1 \& 2: when 20\% load is disconnected and added:-}

The generators are supplying $70 \%$ of load and suddenly a $20 \%$ load is disconnected. As load is reduced so frequency will increase. The disturbance was applied at $\mathrm{t}=50 \mathrm{~s}$. The combined response of all the governors in this situation is shown in Fig. 5. It can be observed that the electro hydraulic PID governor have less overshoot than all others and frequency takes $10.45 \mathrm{~s}$ to reach again to its original $50 \mathrm{~Hz}$ value. The electro hydraulic PI governor has slightly large overshoot and takes $16.25 \mathrm{~s}$ to reach $50 \mathrm{~Hz}$ value. The enhanced governor takes $38.22 \mathrm{~s}$ for coming to a value $50.4 \mathrm{~Hz}$. The mechanical hydraulic governor takes $57.89 \mathrm{~s}$ to reach at value $50.33 \mathrm{~Hz}$. The overshoot and undershoot frequency for different load variations are shown in Fig. 12 \& Fig. 13 (Appendix B). The values of Proportional, Integral and Derivative term for electro hydraulic PID and PI governors are shown in Table I in Appendix B.

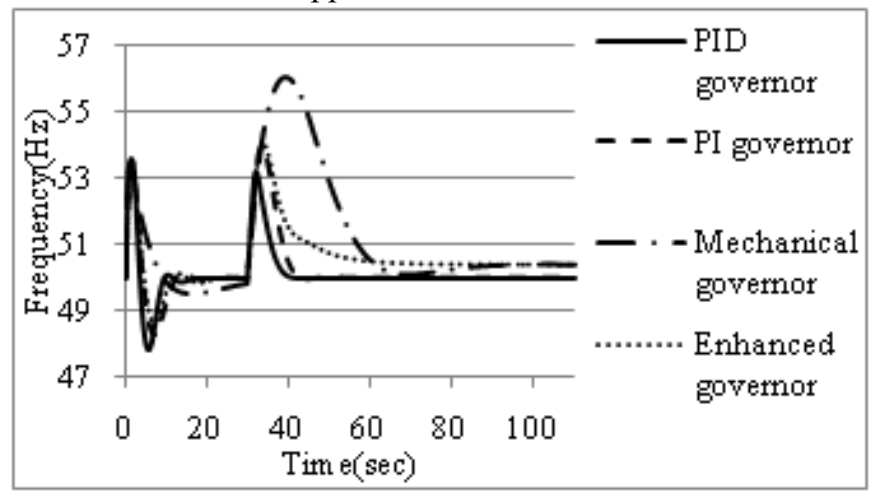

Fig. 5 Governors response for $20 \%$ load reduction.

The response of all governors for an increase of $20 \%$ load is shown in Fig. 6. As the load is increased so frequency will first decrease and then again reaches to its original value after some time interval depending upon the ability of each governor. In this graph mechanical hydraulic governor has again the slow response and having higher undershoot among all. The times taken by the different governors to reach $50 \mathrm{~Hz}$ value are $11.90 \mathrm{~s}, 22.60 \mathrm{~s}, 39.66 \mathrm{~s}$ and $50.95 \mathrm{~s}$ respectively.

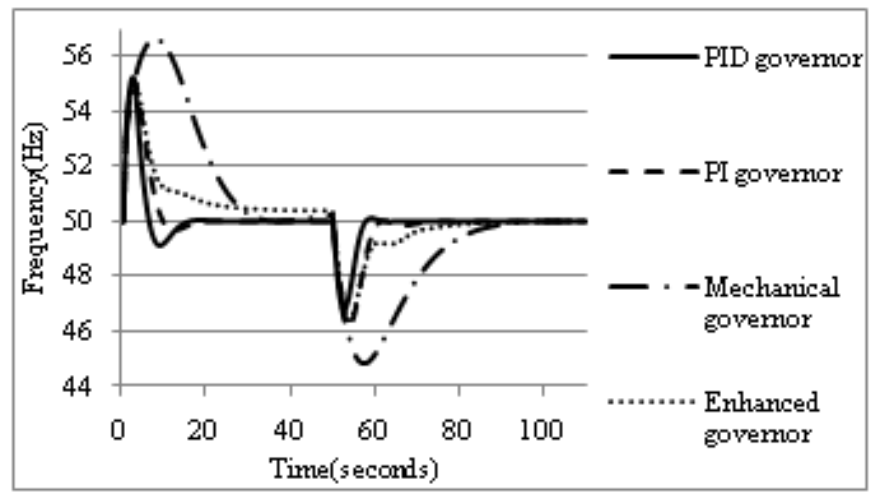

Fig. 6 Governors response for $20 \%$ increase in load.

B. Case\#3 \& 4: when 30\% load is disconnected and added:-

In this case a $30 \%$ load is suddenly disconnected. The disturbance was applied at $\mathrm{t}=50 \mathrm{~s}$. The combined response of all the governors in this situation is shown in Fig. 7. It can be observed that the electro hydraulic PID governor has again the less overshoot than all others and frequency takes $11.61 \mathrm{~s}$ to reach again to its original $50 \mathrm{~Hz}$ value. The electro hydraulic PI governor has slightly large overshoot and takes $15.10 \mathrm{~s}$ to reach $50 \mathrm{~Hz}$ value. The enhanced governor has larger 
overshoot of $56.07 \mathrm{~Hz}$ value and takes $42.8 \mathrm{~s}$ for coming to a value $50.54 \mathrm{~Hz}$. The mechanical hydraulic governor has the poorest response of all, having large overshoot and long settling time to reach at $50.55 \mathrm{~Hz}$ in $78.5 \mathrm{~s}$. The response of enhanced governor and mechanical hydraulic governor shows a huge overshoot and long settling time. The main disadvantage is that the frequency does not reaches to its original value but remains at $50.54 \mathrm{~Hz}$ and $50.55 \mathrm{~Hz}$ respectively all the time. As the frequency range for safety operation is $\pm 0.5 \mathrm{~Hz}$ but these governors show response slightly higher than this limit so these governors cannot work well with such load variations.



Fig. 7 Governors response for $30 \%$ load reduction.

An addition of 30\% load will again result in decrease in frequency from its normal value and large undershoot is observed than previous $20 \%$ increase in load as shown in Fig. 8. The time taken by the electro hydraulic PID and PI governor to attained $50 \mathrm{~Hz}$ value is $15.28 \mathrm{~s}$ and $26.65 \mathrm{~s}$ respectively. In this graph mechanical hydraulic governor has higher undershoot among all and takes $44.21 \mathrm{~s}$ to reach original value whereas enhanced governor has the smaller undershoot than mechanical hydraulic governor but takes more time $50 \mathrm{~s}$ than it.

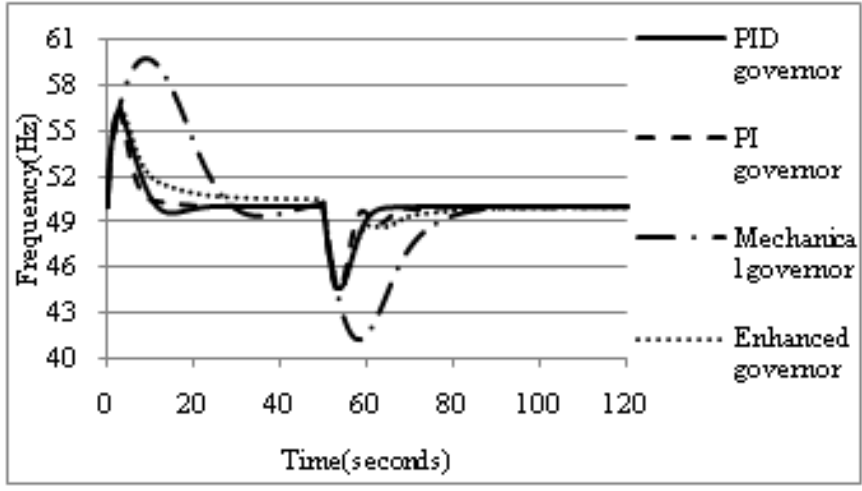

Fig. 8 Governors response for $30 \%$ increase in load.

C. Case\#5 \& 6: when 50\% load is disconnected and added:-

In this case the load is suddenly disconnected by $50 \%$; as a result the frequency of the system increased and very large overshoot is observed. The load disturbance is occurred at $t=$ $50 \mathrm{~s}$. The combined response graph of all governors is shown in Fig. 9. It clearly shows that electro hydraulic PID governor has again the best result in comparison to other three because in this governor the overshoot goes to $58.86 \mathrm{~Hz}$ value and frequency reaches in $19.21 \mathrm{~s}$ followed by electro hydraulic PI governor having overshoot $(59.25 \mathrm{~Hz})$ slightly larger than electro hydraulic PID governor but takes slightly less time $(17.35 \mathrm{~s})$ than electro hydraulic PID governor. The response of enhanced governor is good in overshoot and settling time point of view because it takes $33.47 \mathrm{~s}$ to reach at $50.93 \mathrm{~Hz}$ value and has an overshoot of $59.58 \mathrm{~Hz}$. Mechanical hydraulic governor shows a huge overshoot and long settling time. It takes about $100.33 \mathrm{~s}$ to reach at $50.87 \mathrm{~Hz}$ value and has the maximum overshoot of about $67.95 \mathrm{~Hz}$. The main disadvantage of both these governor is that in their operation the frequency does not come to its original value but remains at $50.93 \mathrm{~Hz}$ and $50.87 \mathrm{~Hz}$ respectively. So these governors cannot be applied practically for long disturbances because of failing in return to its $50 \mathrm{~Hz}$ value and are therefore not suitable for higher reduction/disturbances and islanding operations.

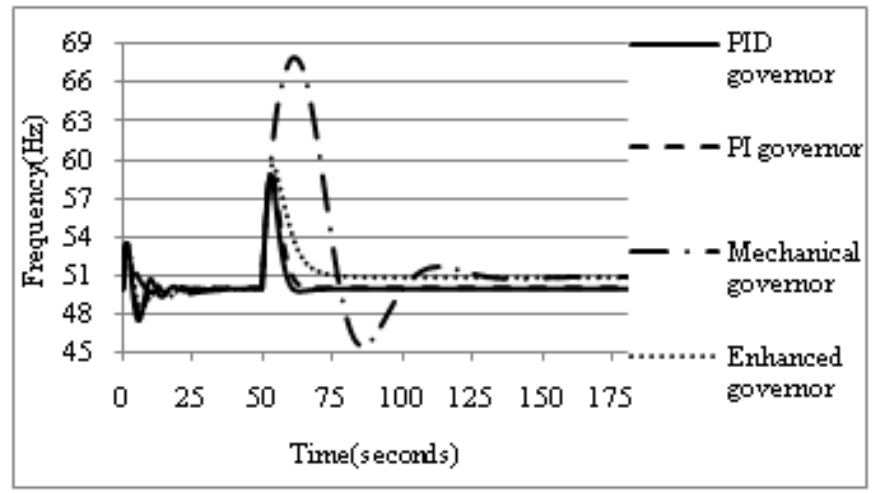

Fig. 9 Governors response for $50 \%$ load reduction.

An addition of $50 \%$ load will again result in further decrease in frequency from its normal value and a very large undershoots is observed than previous $30 \%$ increase in load as shown in Fig. 10. The time taken by the electro hydraulic PID and PI governor to attained $50 \mathrm{~Hz}$ value is $19.66 \mathrm{~s}$ and $20.66 \mathrm{~s}$ respectively. In this graph mechanical hydraulic governor has the highest undershoot $(29.21 \mathrm{~Hz})$ among all and takes $61.73 \mathrm{~s}$ to reach original value. One important point to discuss is that enhanced governor seems to be good in undershoot value than all the governors having undershoot of $41.16 \mathrm{~Hz}$ best even from the electro hydraulic PID governor and takes $51.15 \mathrm{~s}$ to reach to $50 \mathrm{~Hz}$ value. But actually when it operates at $20 \%$ it was operating at $51 \mathrm{~Hz}$ frequency so when $50 \%$ load increased it decreases from 51 to $41.16 \mathrm{~Hz}$ but electro hydraulic PID governor has the best result because it decrease from $50 \mathrm{~Hz}$ to $41 \mathrm{~Hz}$.

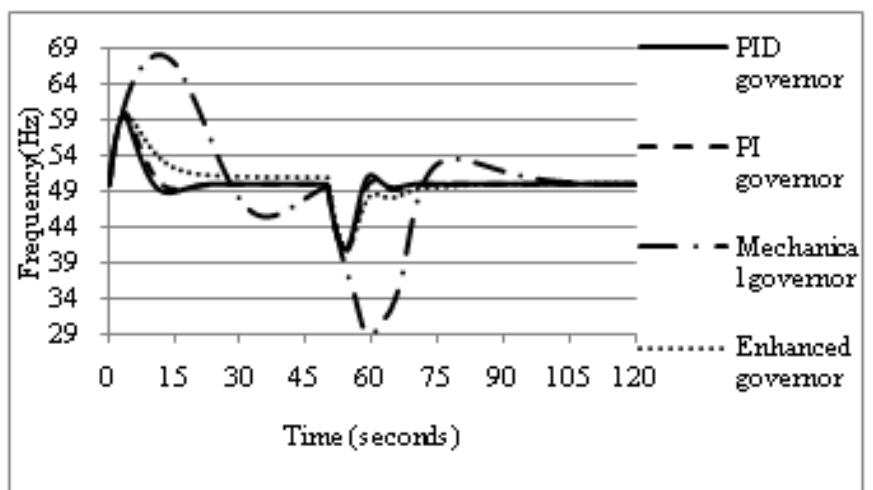

Fig. 10 Governors response for $50 \%$ increase in load 


\section{CONCLUSION:}

The mini hydro-electric energy is the most predictable, clean and free source of renewable energy among the available energy sources. This paper presents the advantages, potential of mini hydro power plants and comparative study on the response of four governors in controlling the system frequency within the range after a load disturbance is occurred.

From the conducted test, it can be concluded that electro hydraulic PID governor shows the best results for large disturbance in load variations followed by electro hydraulic PI governor. The enhanced governor shows much better results in overshoot and settling time than mechanical hydraulic governor. The mechanical hydraulic governor has the poorest response in large load deviations and is not suitable for isolated mode of operation and islanding operation. They can work well if connected with grid, so that the plant supplies a fixed amount of load continuously and the increased load supplied by the grid to meet the load requirements.

\section{APPENDIX A}

\section{Model Data:-}

Apparent power $\quad=2 \mathrm{MVA}$ for each generator System frequency $\quad=50 \mathrm{~Hz}$

Inertia constant of the generator $=3.117 \mathrm{~s}$

$\begin{array}{ll}\text { Line voltage } & =3.3 \mathrm{KV} \\ \text { Rated RMS current } & =0.35 \mathrm{KA}\end{array}$

Transformer capacity $=2 \mathrm{MVA}$

voltage on winding1 $($ delta $)=3.3 \mathrm{KV}$

Voltage on winding2 (star) $=11 \mathrm{KV}$

Head at rated conditions $=1.0 \mathrm{pu}$

Output power at rated conditions $=1.0 \mathrm{pu}$

Gate position at rated conditions $=1.0 \mathrm{pu}$

Rated no load flow $\quad=0.05 \mathrm{pu}$

Initial output power $\quad=0.7$

Initial operating head $=1.0 \mathrm{pu}$

Water starting time $\mathrm{Tw}=2.0 \mathrm{sec}$

Penstock head loss co-efficient $=0.02 \mathrm{pu}$

Turbine damping constant $\mathrm{D}=0.5 \mathrm{pu}$

Permanent droop $=\mathrm{Rp} \quad=0.04 \mathrm{pu}$

Maximum gate position $\mathrm{Gmax}=1.0 \mathrm{pu}$

Minimum gate position $\mathrm{Gmin}=0.0 \mathrm{pu}$

Maximum gate opening rate $(\mathrm{MXGTOR})=0.16 \mathrm{pu} / \mathrm{s}$

Maximum gate closing rate $(\mathrm{MXGTCR})=0.16 \mathrm{pu} / \mathrm{s}$

Pilot valve servomotor time constant $=\mathrm{T}_{\mathrm{A}}$

Or $\mathrm{T}_{\mathrm{P}}=0.05 \mathrm{sec}$ (for electro hydraulic

PID / PI/Mechanical hydraulic governor)

$\mathrm{T}_{\mathrm{P}}=0.02 \mathrm{sec}$ (for enhanced governor)

Gate (Main) servo time constant $=\mathrm{Tc}$ or $\mathrm{T}_{\mathrm{G}}=0.2 \mathrm{sec}$ (for electro hydraulic PID/PI/Mechanical hydraulic governor)

$\mathrm{T}_{\mathrm{G}}=0.5 \mathrm{sec}$ (for enhanced governor)

Gate servomotor time constant $=\mathrm{T}_{\mathrm{D}}=0.2 \mathrm{sec}$

Servo gain $\quad=\mathrm{Q}=5.0 \mathrm{pu}$

Temporary droop $=\mathrm{Rt}=0.4 \mathrm{pu}$ (for mechanical hydraulic governor)

Temporary droop $=\mathrm{Rt}=0.45 \mathrm{pu}$ (for enhanced governor)
Reset or Dashpot time constant $=\mathrm{T}_{\mathrm{R}}=5.0 \mathrm{sec}$ (for mechanical hydraulic governor)

Reset or Dashpot time constant $=T_{R}=0.8 \sec$ (for enhanced governor)

\section{APPENDIX B}

TABLE I

OPTIMUM VALUES OF PI AND PID FOR DIFFERENT LOAD DISTURBANCES

\begin{tabular}{|c|c|c|c|c|c|}
\hline Case & \multicolumn{2}{|c|}{$\begin{array}{c}\text { Electro hydraulic PID } \\
\text { governor Values }\end{array}$} & \multicolumn{2}{c|}{$\begin{array}{c}\text { Electro hydraulic } \\
\text { PI governor } \\
\text { Values }\end{array}$} \\
\hline & $\mathrm{P}$ & $\mathrm{I}$ & $\mathrm{D}$ & $\mathrm{P}$ & $\mathrm{I}$ \\
\hline $\begin{array}{c}20 \% \text { load } \\
\text { reduction }\end{array}$ & 3.0 & 0.7 & 1.4 & 1.9 & 0.4 \\
\hline $\begin{array}{c}20 \% \text { load } \\
\text { addition }\end{array}$ & 2.7 & 0.7 & 1.4 & 1.8 & 0.4 \\
\hline $\begin{array}{c}30 \% \text { load } \\
\text { reduction }\end{array}$ & 3.0 & 0.7 & 0.5 & 2.3 & 0.5 \\
\hline $\begin{array}{c}30 \% \text { load } \\
\text { addition }\end{array}$ & 1.8 & 0.4 & 0.5 & 2.5 & 0.4 \\
\hline $\begin{array}{c}50 \% \text { load } \\
\text { reduction }\end{array}$ & 3.0 & 0.5 & 0.5 & 2.5 & 0.4 \\
\hline $\begin{array}{c}50 \% \text { load } \\
\text { addition }\end{array}$ & 2.2 & 0.5 & 0.5 & 2.0 & 0.4 \\
\hline
\end{tabular}



Fig.11 Distribution test system for islanded operation.

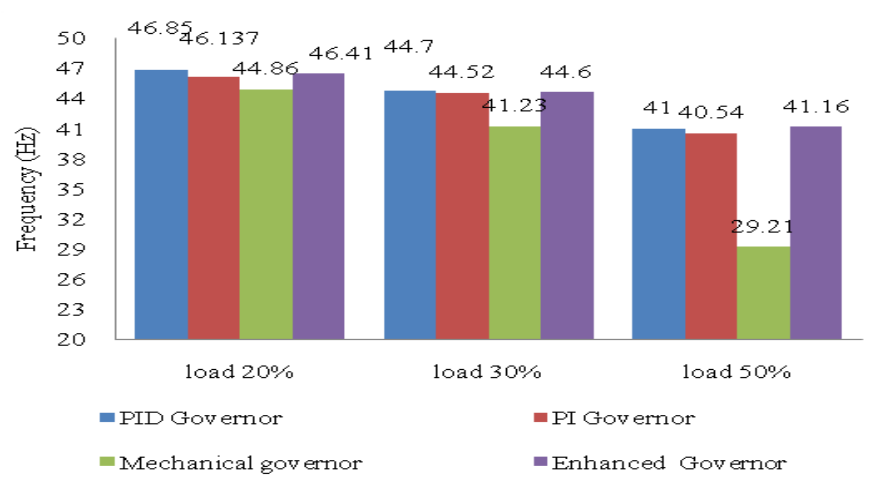

Fig.12 the values of undershoot for different Load (\%) variations 


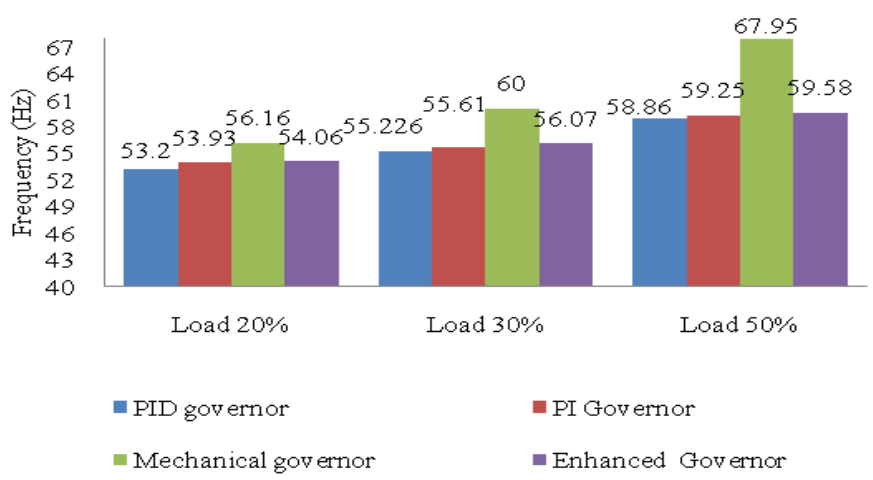

Fig. 13 the values of Overshoot for different Load (\%) variations

\section{REFERENCES}

[1] P. Oliver, "small hydro power: technology and current status," Renew. Sustain. Energy Rev, Vol. 6, pp. 537-556, Dec. 2002

[2] G. J. Ranjitkar, Huang Tung, T., "Application of Micro-Hydropower Technology for Remote Regions," in EIC Climate Change Technology, 2006 IEEE, 2006, pp. 1-10.

[3] J. K. Kaldellis, "The contribution of small hydro power stations to the electricity generation in Greece: Technical and economical considerations", Energy policy 35 (2007) 2187-2196.

[4] S. Fernando, "An assessment of the small hydro potential in Sri Lanka", energy for sustainable development vol. VI, no: 1 march 2002.

[5] Nathan Raman, Ibrahim Hussein, "Reconnaissance study to identify micro hydro potential sites in Malaysia", European journal of scientific research 2010.

[6] F. Schwartz, F. R. Pegallapati, and M. Shahiedehpour, "small hydro as green power", in proc. 2005 IEEE power eng. Soc. General Meeting, pp. 1883-1890

[7] R. Jutras, C. Lafond, M. Plamondon, S. Proulx, and K. Srinivasan, "Islanding tests near a mini hydro generating plant," in proc. 1997 IEEE Industrial and Commercial Power Systems Technical Conference., pp. 91-95.

[8] P. Fuangfoo, L. Wei-Jen, and K.A. Nigim, "Intentional Islanding Operation to Improve the Service Reliability of Thailand Electric Power System," in Power Engineering Society General Meeting, 2007. IEEE, 2007, pp. 1-7.

[9] H. Mohamad, A. H. A. Bakar, H. W. Ping, and H. Mokhlis, "An adaptive controller of hydro generators for smart grid application in Malaysia," in proc. 2010 international conference on Power System Technology (POWERCON), pp. 1-6.

[10] J. Culberg, M. Negnevitsky, and M.A. Kashem, "Hydro-turbine governor control: theory, techniques and limitations," in Proc. 2006, AUPEC'06, Melbourne, pp. 1-5.

[11] D. P. Atherton, S. Majhi, "Limitations of PID controllers", in proceedings of the American conference San Diego, California. June 1999.

[12] I. Salhi, M. Chennani, S. Doubabi, and N. Ezziani, "Modeling and Regulation of micro hydroelectric power plant", IEEE 2008.

[13] Working group on prime mover, "Hydraulic turbine and turbine controls models for system dynamic studies" IEEE Transactions on power systems, Vol. 7, No. 1, February 1992.

[14] IEEE Power Engineering Society, "EEE Std1207: IEEE Guide for the application of turbine governing systems for hydro electric generating units", Energy Development and power generation committee, Nov. 2004

[15] IEEE guide for control of small hydroelectric power plants, Std 10201988.

[16] IEEE Committee Report, "Dynamic models for steam and hydro turbines in power system studies", IEEE Transactions on power Apparatus and Systems, 1973, pp-1904-1915.

[17] P. Kundur, Power System Stability and Control, McGraw-Hill,1994
[18] N. Kishor, R. P. Saini, and S. P. Singh, "A review on hydropower plant models and control," Renewable and Sustainable Energy Reviews, vol. 11, pp. 776-796, 2007.

[19] D. Henderson, "An advanced electronic load governor for control of micro hydroelectric generation," Energy Conversion, IEEE Transactions on, vol. 13, pp. 300-304, 1998.

[20] S. Doolla and T. S. Bhatti, "Load Frequency Control of an Isolated Small-Hydro Power Plant With Reduced Dump Load," Power Systems, IEEE Transactions on, vol. 21, pp. 1912-1919, 2006.

[21] S. Doolla and T. S. Bhatti, "Automatic generation control of an isolated small-hydro power plant," Electric Power Systems Research, vol. 76, pp. 889-896, 2006. 